\title{
Development of a multi-excitation fluorescence (MEF) imaging method to improve the information content of benthic coral reef surveys
}

\author{
Elena Bollati ${ }^{1,2}$ - Cecilia D'Angelo ${ }^{1,3}$ - David I. Kline ${ }^{4}$ - B. Greg Mitchell ${ }^{5}$. \\ Jörg Wiedenmann ${ }^{1,3}$ (1)
}

Received: 1 October 2020/Accepted: 15 April 2021/Published online: 6 September 2021

(C) The Author(s) 2021

\begin{abstract}
Benthic surveys are a key component of monitoring and conservation efforts for coral reefs worldwide. While traditional image-based surveys rely on manual annotation of photographs to characterise benthic composition, automatic image annotation based on computer vision is becoming increasingly common. However, accurate classification of some benthic groups from reflectance images presents a challenge to local ecologists and computers alike. Most coral reef organisms produce one or a combination of fluorescent pigments, such as Green Fluorescent Protein (GFP)-like proteins found in corals, chlorophyll-a found in all photosynthetic organisms, and phycobiliproteins found in red macroalgae, crustose coralline algae (CCA) and cyanobacteria. Building on the potential of these pigments as a target for automatic image annotation, we developed a novel imaging method based on off-the-shelf components to improve classification of
\end{abstract}

Topic Editor Stuart Sandin

Jörg Wiedenmann

joerg.wiedenmann@noc.soton.ac.uk

1 Coral Reef Laboratory, University of Southampton, Waterfront Campus, European Way, Southampton SO14 3ZH, UK

2 Department of Biological Sciences, National University of Singapore, 16 Science Drive 4, Singapore 117558, Singapore

3 Institute for Life Sciences, University of Southampton, Highfield Campus, Southampton SO17 1BJ, UK

4 Smithsonian Tropical Research Institute, Luis Clement Avenue, Bldg. 401 Tupper Balboa Ancón, Panama, Republic of Panama

5 Integrative Oceanography Division, Scripps Institution of Oceanography, University of California San Diego, La Jolla, CA, USA coral and other biotic substrates using a multi-excitation fluorescence (MEF) imaging system. We used RGB cameras to image the fluorescence emission of coral and algal pigments stimulated by narrow-waveband blue and green light, and then combined the information into three-channel pseudocolour images. Using a set of a priori rules defined by the relative pixel intensity produced in different channels, the method achieved successful classification of organisms into three categories based on the dominant fluorescent pigment expressed, facilitating discrimination of traditionally problematic groups. This work provides a conceptual foundation for future technological developments that will improve the cost, accuracy and speed of coral reef surveys.

Keywords Functional imaging - Survey methods - GFP . Phycoerythrin · Chlorophyll · CCA

\section{Introduction}

Coral reefs and the vital ecosystem services they provide are increasingly threatened by human activity (Hughes et al. 2018). Establishing baselines and monitoring the effectiveness of management and restoration efforts through ecological surveys is paramount to the success of coral reef conservation. Therefore, there is a need for methodologies that can provide accurate characterisation of coral reef benthic assemblages in a timely and reproducible manner.

In the early days, classification of coral reef benthos was based on data collected manually by divers; however, image-based survey methods rapidly became more common as they allow larger areas to be surveyed using less inwater time and fewer operators, and they provide a 
permanent visual record of the survey site, which can be reanalysed when required (Jokiel et al. 2015). Analysis of benthic imaging datasets requires that the organisms and substrates encountered are identified, and the images annotated; however, a number of issues are associated with annotation of coral reef imaging data. First, imaging datasets can be very large, to the point that years of analysis would be required if relying on manual annotation alone (González-Rivero et al. 2014). To overcome this bottleneck, computer vision and machine learning methods have been applied to coral reef benthic datasets in an effort to automate the image annotation process (Mehta et al. 2007; Pizarro et al. 2008; Stokes and Deane 2009; Beijbom et al. 2012, 2015; Shihavuddin et al. 2013).

A second issue is that for some groups of benthic organisms, identification from photographs is problematic even when performed by experts (Ninio et al. 2003; Beijbom et al. 2015). The lowest classification accuracy is often found within algal groups, particularly between turf and crustose coralline algae (CCA) (Beijbom et al. 2012, 2015; Mahmood et al. 2016); this has led some studies to treat algae as a single group for the purposes of classification, or to group CCA with abiotic substrates (Soriano et al. 2001; Stokes and Deane 2009; Beijbom et al. 2016). From a functional perspective, however, these organisms are widely distinct. For example, CCA contribute to reef accretion (Goreau 1963; Bak 1976), produce settlement cues for coral larvae (Morse et al. 1988; Heyward and Negri 1999) and are often the main substrateforming species in high-energy environments such as intertidal reef crests (Tracey et al. 1948). CCA are also sensitive to a number of anthropogenic stressors, including sedimentation, warming and ocean acidification (Fabricius and De'ath 2001; Anthony et al. 2008; Jokiel et al. 2008; Kuffner et al. 2008). In contrast, non-calcifying benthic algae can proliferate and outcompete corals in response to nutrient enrichment, can inhibit coral recruitment and are associated with reduced coral cover and calcification (Loya 2004; Fabricius 2005; Kuffner et al. 2006; D’Angelo and Wiedenmann 2014). The ability to accurately classify algal groups in imaging surveys is thus of relevance for monitoring and management of reef ecosystems.

A number of imaging techniques have been developed to improve the identification and automatic classification of functional benthic groups, many of which rely on knowledge of the optical properties of reef organisms and abiotic substrates (Strand et al. 1997; Gleason et al. 2007; Treibitz et al. 2015; Chennu et al. 2017). One example is multispectral or hyperspectral imaging, where reflectance images acquired in specific wavebands are used to facilitate classification (Gleason et al. 2007; Chennu et al. 2017). This approach can also be implemented from airborne remote sensing platforms (Andréfouët et al. 2004; Kutser et al. 2006; Garcia et al. 2018); however, specialised and often expensive imaging equipment is required. As an alternative approach, some studies have focused on imaging endogenous fluorescence of reef organisms to complement (or replace) reflectance imaging data (Strand et al. 1997; Mazel et al. 2003; Treibitz et al. 2015; Beijbom et al. 2016). Endogenous fluorescence is a promising target for functional imaging of coral reefs in situ because functionally distinct groups of organisms produce optically distinct sets of fluorescent pigments. Field studies have shown that targeting these pigments can enable or even improve automatic classification compared to reflectance imaging alone (Mazel et al. 2003; Beijbom et al. 2016). Hard corals and other cnidaria accumulate high concentrations of Green Fluorescent Protein (GFP)-like proteins with cyan, green or orange-red emission bands (Matz et al. 1999; Wiedenmann et al. 2000, 2002; Dove et al. 2001; Oswald et al. 2007; Alieva et al. 2008), while algae predominantly emit fluorescence in the red emission band of chlorophyll-a. Importantly, different groups of algae present distinct excitation spectra due to coupling of accessory pigments such as chlorophyll-b (green algae), chlorophyllc (brown algae) or phycobiliproteins (phycoerythrin (PE) and phycocyanin (PC) in red macroalgae, CCA and cyanobacteria) (French and Young 1952; Myers and Kratz 1955; Falkowski and Kiefer 1985). While being linked to their genetic background, the fluorescence of many reef organism has been shown to respond to physical drivers, most prominently to light (Falkowski and Kiefer 1985; Salih et al. 2000; D'Angelo et al. 2008; Gittins et al. 2015; Bollati et al. 2017, 2020; Smith et al. 2017; Quick et al. 2018), making it a promising physiological marker of environmental change (D'Angelo et al. 2012; Zawada and Mazel 2014).

So far, efforts to include fluorescence data in benthic imaging surveys have used monochromatic or narrowwaveband blue light to excite fluorescence in multiple emission bands, separated either by interference filters on a multispectral imager (Strand et al. 1997; Mazel et al. 2003) or by the intrinsic colour sensitivity of an RGB camera (Treibitz et al. 2015; Beijbom et al. 2016). With the former method, Mazel et al. (2003) were able to separate CCA from other photosynthetic organisms using the orange emission band of PE; however, their imaging system was a highly specialised laser line scanner (Strand et al. 1997), making this method not easily accessible to many endusers in the conservation and management sector. The latter method used off-the-shelf professional photography equipment but only allowed discrimination between coral GFP and chlorophyll fluorescence (Treibitz et al. 2015; Beijbom et al. 2016).

In this laboratory-based study, we present a novel imaging method to target fluorescent pigments expressed 
by functionally distinct groups of benthic marine organisms. The method is entirely based on off-the-shelf components in order to ensure maximum reproducibility and accessibility to a variety of end-users. We propose that acquiring fluorescence images in two excitation (blue and green) and two emission (green and red) channels can provide spectral separation between GFP-like proteins, chlorophyll and PE, and that this information can be used to inform algorithms for automatic classification. We hypothesise that the two emission channels can discriminate between coral FPs and algal photosynthetic pigments, while the addition of two excitation channels can provide differentiation between functional groups of algae based on their dominant accessory pigment. We use a proof-ofconcept configuration to image a range of coral reef organisms, and evaluate the concept in a laboratory setting under tightly controlled conditions.

\section{Materials and Methods}

\section{Imaging system configuration}

Two high-power LEDs (Luxeon Rebel in Royal Blue, peak wavelength $(\lambda)=450 \mathrm{~nm}$, full width at half maximum $(\mathrm{FWHM})=40 \mathrm{~nm}$, and Green, $\lambda=530 \mathrm{~nm}, \mathrm{FWHM}=60$ nm. Lumileds, San Jose, CA, USA. Figure 1a) were soldered onto single-diode star printed circuit boards (Bergquist, Chanhassen, MN, USA), mounted onto a $2.5 \mathrm{~cm}$ anodised aluminium heat sink (Ohmite, Warrenville, IL, USA), and ran at $350 \mathrm{~mA}$ using a constant current driver (PowerLED, Aldermaston, UK). The LED modules were fitted with plastic connectors to enable alternate coupling of each LED into an optical fibre connected to a $66 \mathrm{~mm}$ microscope ring light (Leica Microsystems, Milton Keynes, UK), which was mounted onto the objective of a fluorescence microscope (MZ10 F, Leica Microsystems, Milton Keynes, UK) (Fig. S1). For reflectance images, a photonic cold light source (Leica Microsystems, Milton Keynes, UK) was used with the same fibre and ring light. The LED light sources produced a photon irradiance of $49 \mu \mathrm{mol}$ photons $\mathrm{m}^{-2} \mathrm{~s}^{-1}$ (450 nm LED) and $28 \mu \mathrm{mol}$ photons $\mathrm{m}^{-2} \mathrm{~s}^{-1}(530 \mathrm{~nm})$ when the microscope was focused on the surface of a $180^{\circ}$ quantum sensor attached to a PAR light meter (Li-Cor, Lincoln, NE, USA). Relative irradiance spectra of the LEDs were measured with a USB 4000 modular spectrometer (Ocean Optics, Dunedin, FL, USA).

\section{Sample origin}

Fronds of Codium sp. (Stackhouse 1797) and Solieria chordalis (C. Agardh) J. Agardh 1842 were collected from the intertidal shore in Portland, UK, frozen and maintained at $-20{ }^{\circ} \mathrm{C}$ before processing. Live corals and algae were obtained from the UK ornamental trade and cultured long term in the Coral Reef Laboratory coral reef mesocosm at the National Oceanography Centre, Southampton, UK (D'Angelo and Wiedenmann 2012), or provided by the Scripps Photobiology Group (Scripps Institution of Oceanography, UCSD) and the Birch Aquarium at Scripps (La Jolla, CA).

\section{Algal pigment extraction}

Frozen fronds were homogenised with a pestle and mortar in $0.1 \mathrm{M}$ sodium phosphate buffer ( $\mathrm{pH} 7.4$ ). For extraction of Codium lipid-soluble pigments, $0.5 \mathrm{~mL}$ saturated $\mathrm{MgCO}_{3}$ solution was added to the mortar to prevent pheophytinisation (Strickland and Parson 1972). Pigments were extracted in $90 \%$ acetone at $-20{ }^{\circ} \mathrm{C}$ for $1 \mathrm{~h}$, and debris was removed by centrifugation (3 min, $2000 \mathrm{rcf}$, $4{ }^{\circ} \mathrm{C}$, twice). For water-soluble pigment extraction from Solieria chordalis, homogenisation was followed by $5 \mathrm{~min}$ sonication on ice in $30 \mathrm{~s}$ bursts; the extract was then clarified by centrifugation $\left(3 \mathrm{~min}, 2000 \mathrm{rcf}, 4{ }^{\circ} \mathrm{C}\right.$, twice, followed by $45 \mathrm{~min}, 20,000 \mathrm{rcf}, 4^{\circ} \mathrm{C}$ ). All samples were frozen at $-20^{\circ} \mathrm{C}$ before further analysis.

\section{Coral GFP-like protein expression and purification}

Fluorescent proteins amilFP497 and amilFP597 from Acropora millepora (Ehrenberg 1834) (D'Angelo et al. 2008) and EechRFP from Echinophyllia echinata (SavilleKent 1871) (Alieva et al. 2008) were produced in a bacterial expression system as described by Wiedenmann et al. (2002). For amilFP497 and amilFP597, the clarified supernatant was used for imaging. EechRFP was purified from the clarified supernatant and desalted as described by Bollati et al. (2017); partial photoconversion was induced by placing the purified protein under a $412 \mathrm{~nm}$ LED (Aquaray NUV, TMC, London, UK) for $10 \mathrm{~min}$ (Wiedenmann et al. 2004; Bollati et al. 2017).

\section{Fluorescence spectroscopy}

Excitation/emission spectra of purified or extracted pigments were measured with a fluorescence spectrophotometer (Cary Eclipse, Agilent, Santa Clara, CA, USA) in a $10 \mathrm{~mm}$ quartz cuvette. For pigment characterisation, all emission spectra were collected using $450 \mathrm{~nm}$ excitation to match the narrow-waveband blue excitation light of our imaging system, and excitation spectra were measured across the entire emission spectrum (zero order) to match the broad detection range of our camera sensor. 


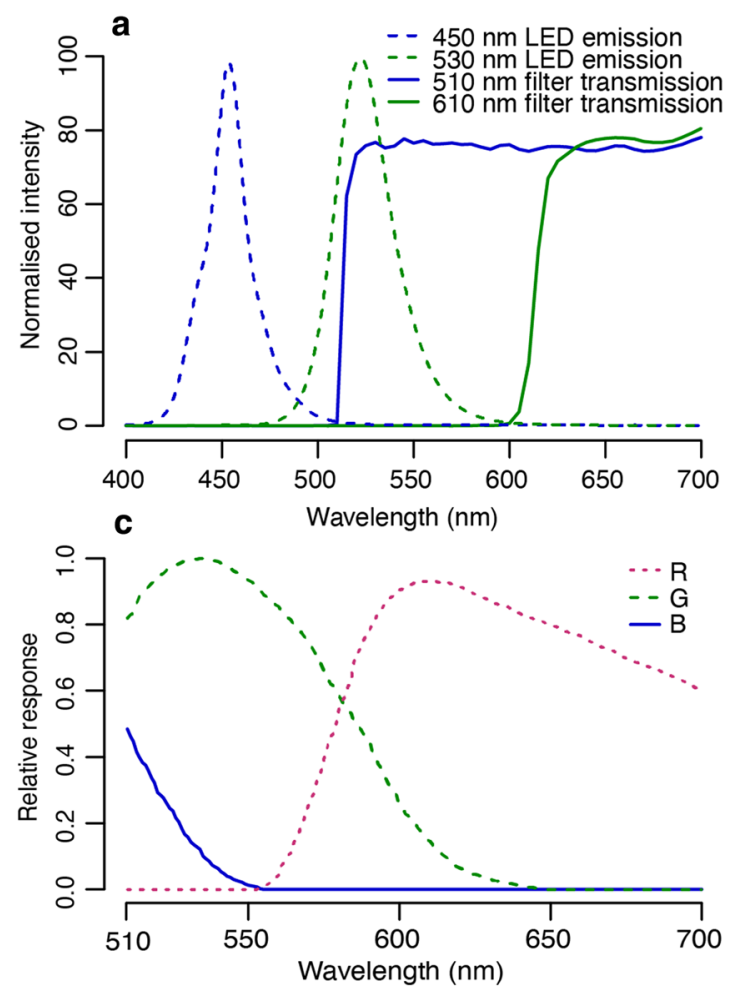

Fig. 1 Spectral properties of the MEF imaging system. a Relative spectral intensity of excitation light sources (dashed lines) and transmission spectra of emission filters (solid lines) used for

Excitation/emission spectra of live corals and algae were measured by coupling the spectrophotometer with a fibre optic probe (D'Angelo et al. 2008); one excitation and one emission spectrum were collected for each specimen imaged with the microscope camera set-up. Emission/excitation wavelength used for measurement is presented in Table 1.

\section{Microscopic imaging}

Images of purified pigments in a micro-well plate and of live organisms were taken with a CCD camera (DFC 420 C, Leica Microsystems, Milton Keynes, UK) through the fluorescence microscope (Fig. S1). Live organisms were kept in seawater, while the objective remained dry. The wheel-mounted emission filters used were a long-pass UV filter for reflectance images (cut-on $420 \mathrm{~nm}$ ), a GFPplus filter for $450 \mathrm{~nm}$ images, and a Texas Red filter for $530 \mathrm{~nm}$ images (Fig. 1a); filter transmission spectra were measured with a UV-Vis spectrophotometer (Cary 50, Agilent, Santa Clara, CA, USA).

Extracted/purified pigments were imaged with an exposure time of $6 \mathrm{~s}$, as were all live algae and the brown morph of M. foliosa; all other corals were imaged with an exposure time of $980 \mathrm{~ms}$. Images for background correction were collected using the same exposure times; an

b

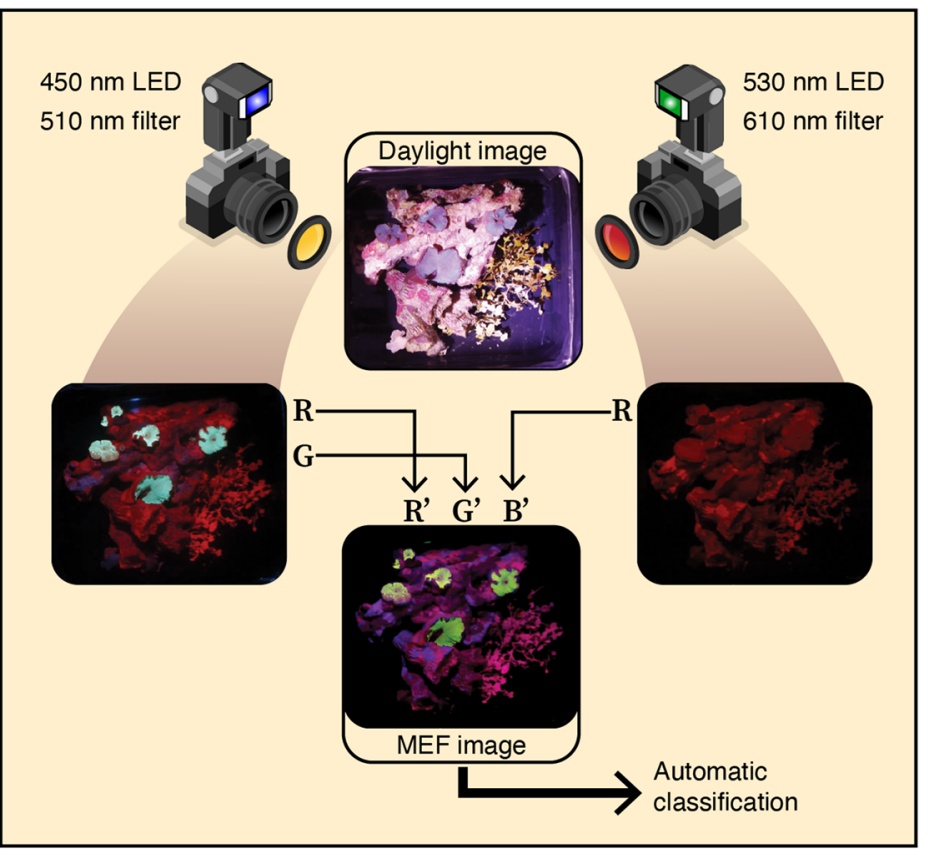

microscope image collection. b The MEF image acquisition and processing pipeline. c Relative spectral sensitivity of the $R, G$, and $B$ channel of the microscope camera CCD sensor

empty well was imaged as background for purified pigments, while a black nonreflective material was used for live organisms.

\section{Compact camera imaging}

Macroscopic images were taken with a compact camera (TG4, Olympus, Tokyo, Japan) in aperture priority mode, mounted on a tripod; illumination was from the same ringlight system, fixed $\sim 20 \mathrm{~cm}$ above the subject. Organisms were placed in seawater while the camera remained dry. Emission filters were held in front of the camera lens; plastic long-pass filters (Nightsea, Lexington, MA, USA) were used to image purified pigments in a 96-well plate. The wider-angle image of an assemblage of tropical benthic organism was obtained using gel emission filters (\#10 Medium Yellow and \#19 Fire, Rosco, Stamford, CT, USA. Fig. S2) to avoid distortion produced by the convex plastic filters. A well containing water was used for background correction of the purified pigment image, and an area of the tank free from organisms was used for background correction of the reef assemblage image. 
Table 1 Spectral properties of extracted and purified pigments and live organisms. $\lambda=$ peak wavelength $(\mathrm{nm})$, em $=$ emission, ex $=$ excitation Extracted or purified pigments (in vitro)

\begin{tabular}{llll}
\hline Pigment & Species & Excitation $\lambda(\mathrm{em}=0$ order) & Emission $\lambda(\mathrm{ex}=450 \mathrm{~nm})$ \\
\hline Chlorophyll extract & Codium sp. & 659,665 & 652 \\
Phycobiliprotein extract & S. chordalis & 497,564 & 572 \\
Purified amilFP497 & A. millepora & 479 & 493 \\
Purified amilFP597 & A. millepora & 559 & 503,587 \\
Purified eechRFP & E. echinata & 507,571 & 516,579 \\
Living organisms (in vivo) & & & 2 \\
Group & Species & Excitation $\lambda($ emission) & Emission $\lambda($ excitation) \\
Green algae & Caulerpa sp. & $480(680)$ & $683(476)$ \\
Red algae & Unidentif. fleshy & $570(680)$ & $579,654(476)$ \\
Red algae & Unidentif. CCA & $565(680)$ & $581(476)$ \\
Red coral & Oxypora sp. & $507,571(590)$ & $515,581(470)$ \\
Green coral & A. millepora & $500(550)$ & $514(435)$ \\
Green coral & P. lichen & $461(550)$ & $489,678(450)$
\end{tabular}

\section{FluorIS imaging}

Images were taken with a 5D Mark-II camera (Canon, Tokyo, Japan), modified to increase far-red sensitivity and mounted on a framer as described by Treibitz et al. (2015). Illumination was provided by LED modules also mounted on the framer (Luxeon Z, Royal Blue and Cyan$\lambda=505 \mathrm{~nm}$, FWHM $=40 \mathrm{~nm}$. Lumileds, San Jose, CA, USA). Gel emission filters (\#10 Medium Yellow and \#19 Fire, Rosco, Stamford, CT, USA) were held in front of the Sigma $20 \mathrm{~mm} / 1.4$ lens with filter holders. The spectral properties of these components (Fig. S3) matched those used with the microscope and compact camera, with the exception of the $530 \mathrm{~nm}$ LED which was replaced by a $505 \mathrm{~nm}$ one. All images were acquired with aperture $f=3.5$, shutter speed $1 / 30 \mathrm{~s}$ and ISO800. A square of white card placed within the frame was used for background correction for both images. Organisms were imaged in seawater (with the exception of macroalgae samples, which were placed on a piece of black cardboard in air) while the camera remained dry.

\section{Image processing}

To convert $450 \mathrm{~nm}$ and $530 \mathrm{~nm}$ image pairs into R' G'B' images, each 8-bit RGB image was first split into the 3 colour channels. The $\mathrm{R}$ and $\mathrm{G}$ channels of the $450 \mathrm{~nm}$ image and the $\mathrm{R}$ channel of the $530 \mathrm{~nm}$ image were background corrected by subtracting the mean pixel intensity of the corresponding background images from every pixel, then merged into a new 8-bit RGB image (the R'G'B' image).
Pixel intensity of extracted/purified pigment images in each channel was measured using software Fiji (Schindelin et al. 2012) and compared to calculated estimates (see Supplementary Methods) using a Pearson's product-moment correlation test.

Classification rules were manually defined after plotting the $R^{\prime} / G^{\prime}, R^{\prime} / B^{\prime}$ and $G^{\prime} / B^{\prime}$ ratios of purified pigments in a 3D space. The rules were selected to be exclusive, so it would not be possible for a pixel to be classified as more than one category. The background value was set to 20 for all channels and all categories. The classification algorithm was implemented in MATLAB.

Images obtained with the compact camera and the FluorIS were registered using the ImageJ plugin StackReg (Thévenaz et al. 1998) to compensate for the convex emission filter and for any small movements of the camera. FluorIS R'G'B' images were further normalised to the highest pixel value in order to brighten the images without modifying the ratios between channels.

\section{Results}

\section{The multi-excitation fluorescence (MEF) imaging and image processing concept}

The MEF imaging system is designed to acquire two separate fluorescence images for each subject, one under blue and one under green excitation. The excitation light sources are two narrow-waveband, high-power LEDs with peak wavelength at $450 \mathrm{~nm}$ (blue) and $530 \mathrm{~nm}$ (green) (Fig. 1). The blue excitation $(450 \mathrm{~nm})$ images are acquired through a yellow long-pass emission filter with a cut-on wavelength 
of $\sim 510 \mathrm{~nm}$, and the green excitation $(530 \mathrm{~nm})$ images through a red long-pass filter with a cut-on wavelength of $\sim 610 \mathrm{~nm}$ (Fig. 1a, b); the filters are designed to minimise bleed-through of excitation light, either direct or backscattered by the objects imaged. For the initial proofof-concept study, we coupled the excitation lights into the illumination system of a fluorescence microscope and used the microscope CCD camera for imaging (Fig. S1). Due to the spectral sensitivity of the RGB camera sensor (Fig. 1c), the $510 \mathrm{~nm}$ filter excludes the majority of wavelengths that would produce signal in the B channel, as does the $610 \mathrm{~nm}$ filter for both B and G channels (Fig. 1a, c). All meaningful fluorescence signal from both images can thus be stored as a single three-channel image; therefore, we processed the image pairs acquired with $450 \mathrm{~nm}$ and $530 \mathrm{~nm}$ excitation as pseudocolour RGB images and defined the new colour space as R'G'B' (Fig. 1b), where:

$\mathrm{R}^{\prime}=450 \mathrm{~nm}$ excitation, $\mathrm{R}$ channel.

$\mathrm{G}^{\prime}=450 \mathrm{~nm}$ excitation, $\mathrm{G}$ channel.

$\mathrm{B}^{\prime}=530 \mathrm{~nm}$ excitation, $\mathrm{R}$ channel.

We included a channel-specific background correction step to account for differences in the bleed-through of each light/filter combination.

\section{Fluorescence of purified marine pigments}

To evaluate the ability of the MEF system to detect fluorescence spectra that are relevant for reef surveys, we isolated and characterised marine fluorescent pigments representative of different benthic categories. The key pigment groups were represented by acetone-extracted chlorophylls from Codium sp., aqueous phycobili protein extracts from $S$. chordalis, and purified recombinant proteins of major FP colour classes (amilFP497 as cyan/green cnidarian fluorescent protein (CFP/GFP), amilFP597 as red cnidarian fluorescent protein (RFP), and eechRFP as cnidarian photoconvertible red fluorescent protein (pcRFP)) (Fig. 2, Table 1).

Extracted chlorophyll presented a single emission peak at $652 \mathrm{~nm}$, with excitation maxima at 659 and $665 \mathrm{~nm}$ and lowest excitation values between 500 and $550 \mathrm{~nm}$ (Fig. 2, Table 1). These values are indicative of the presence of both chlorophyll-a and $b$, with the latter being more efficiently excited by the $450 \mathrm{~nm}$ measuring light thus causing an apparent hypsochromic shift in the emission spectrum compared to the excitation spectrum (Jeffrey et al. 1997). The emission spectra of the aqueous red alga extracts presented a single peak at $572 \mathrm{~nm}$ and excitation maxima at 497 and $564 \mathrm{~nm}$, confirming that the extract contained mostly PE (French and Young 1952). Spectra of Acropora millepora FPs presented excitation/emission maxima at $479 \mathrm{~nm} / 493 \mathrm{~nm}$ for amilFP497 and $559 \mathrm{~nm} / 587 \mathrm{~nm}$ for
amilFP597; eechRFP spectra showed contributions from a green and a red species, with peaks at $507 \mathrm{~nm} / 516 \mathrm{~nm}$ and $571 \mathrm{~nm} / 579 \mathrm{~nm}$, respectively (Fig. 2, Table 1).

We then used the MEF system to image aliquots of the same purified pigments under $450 \mathrm{~nm}$ and $530 \mathrm{~nm}$ excitation and processed the images acquired into R' $\mathrm{G}^{\prime} \mathrm{B}$ ' format (Fig. 2). Imaging of chlorophyll extract and amilFP497 produced signal almost exclusively in the R' and G' channels, respectively; PE, amilFP597, and eechRFP produced signal in all three channels, with variable intensity (Fig. 2). The pixel intensity measured from R'G'B' images showed a strong significant correlation with estimates of R'G'B' intensity that were mathematically derived from the excitation/emission spectra (Pearson's product-moment, $r_{13}=0.88, p<0.001$ ), indicating the suitability of the R'G'B' format to convey spectral information (Fig. S4).

\section{Definition of classification rules}

We then explored the possibility of using the R'G'B' image format to automatically classify benthic organisms into categories based on the dominant fluorescent pigment present. As it was not practical to obtain a dataset large enough to train and test a computer vision model with our prototype imaging system, we adopted the approach of defining a set of a priori classification rules using the R'G'B' intensity measured for extracted/purified pigments (Fig. 2).

To define the set of rules, we first described each pigment by its R'G'B' pixel intensity ratios R'/G', R'/B', and G'/B' (Fig. 3). In this colour space, chlorophyll was strongly separated from the other pigments by its much higher R'/B' and R'/G' values; amilFP497 was characterised by $\mathrm{G}^{\prime} / \mathrm{B}^{\prime}>>1$, and $\mathrm{R}^{\prime} / \mathrm{G}^{\prime}<<1$; $\mathrm{PE}$, amilFP597, and eechRFP clustered together due to similar $\mathrm{R}^{\prime} / \mathrm{B}^{\prime}$ values between 1 and 2, but with some separation in the R'/G' and G'/B' dimensions (Fig. 3). Based on these values, we arbitrarily defined regions in the $R^{\prime} G^{\prime} B^{\prime}$ ' ratio colour space for broad classification into three categories: $C h l, C F P / G F P$, and RFP/PE (Table 2, Fig. 3).

The G'/B' ratio was ignored in the definition of the $C h l$ category, as was the $\mathrm{R}^{\prime} / \mathrm{B}^{\prime}$ ratio for $C F P / G F P$, since the respective extracted/purified pigments had only background signal in these channels (Fig. 2). Although R' G'B' images were background corrected during initial processing, we also set a minimum intensity threshold in the relevant channels for each category in order to exclude low intensity pixels produced by bleed-through of reflected excitation light (Table 2). We defined an Other category to classify pixels with above-threshold intensity in any channel, but with channel ratios that did not match any of the three explicit categories. Pixels with below-threshold 


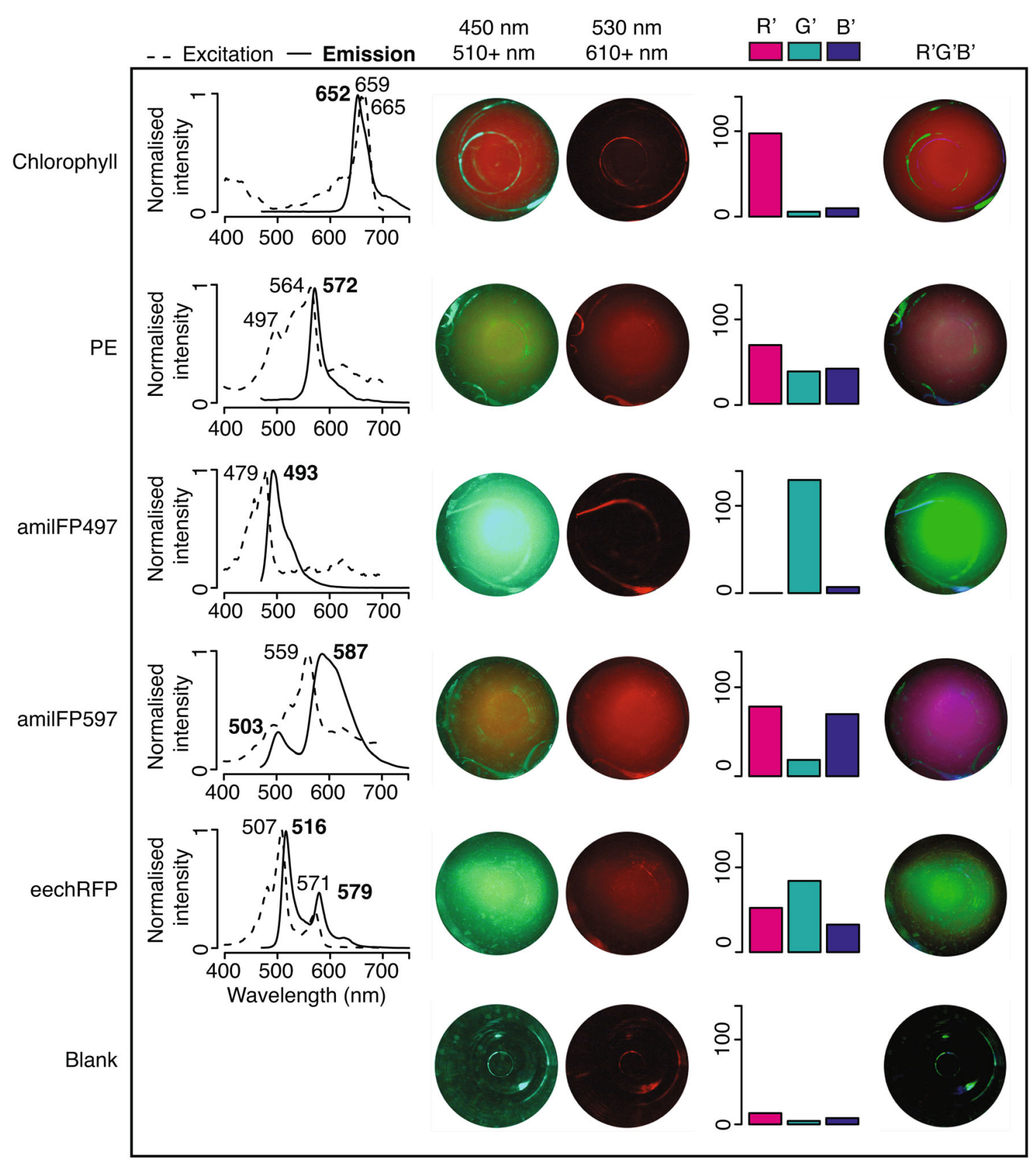

Fig. 2 Spectral characterisation and MEF imaging of isolated marine pigments. Excitation $(E x$, emission $=$ zero order $)$ and emission $(\mathbf{E m}$, Excitation $=450 \mathrm{~nm}$ ) spectra with peak wavelength in $\mathrm{nm}$; pigments imaged with the CCD camera under $450 \mathrm{~nm}(510 \mathrm{~nm}$ emission filter)

intensity in all three channels were considered to have no signal.

\section{Classification of live organisms}

We then collected spectral data and MEF images for a range of coral reef benthos, including green and red algae, $\mathrm{CCA}$, and a number of coral species. We converted the $450 \mathrm{~nm} / 530 \mathrm{~nm}$ image pairs into R'G'B' images and and $530 \mathrm{~nm}$ excitation (610 nm emission filter), barplot of pixel intensity in the R', G', and B' channels, and the resulting combined R'G'B' images

applied the classification algorithm (Figs. 4, 5, S5, Table 2). Green algae had chlorophyll-like emission spectra and excitation maxima $<500 \mathrm{~nm}$ and correspondingly showed stronger red fluorescence under $450 \mathrm{~nm}$ light (Fig. 4a, Table 1). Red algae, which present the excitation/ emission signature of PE as well as the emission signature of chlorophyll, appeared brighter under $530 \mathrm{~nm}$ light (Fig. 4b, Table 1). CCA spectra had a stronger PE emission contribution and they were strongly fluorescent in both 


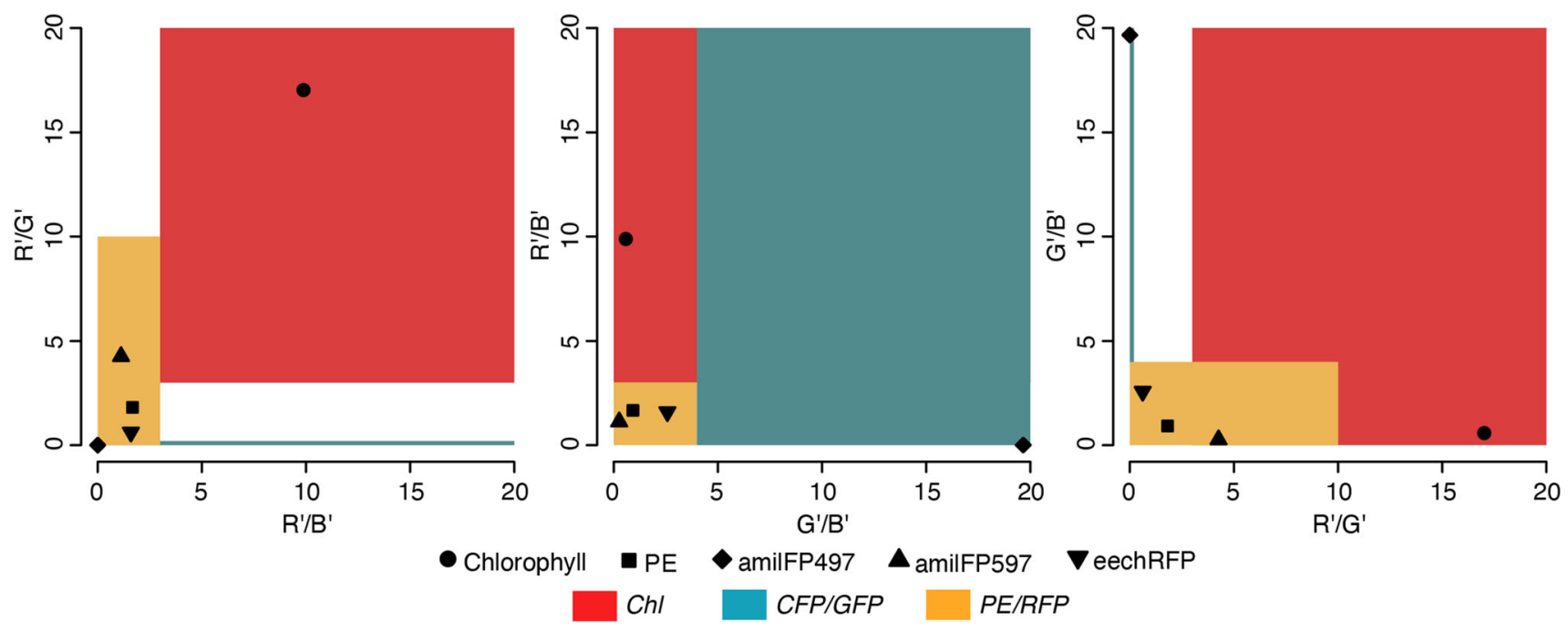

Fig. 3 R'G'B' ratios of purified pigments and of categories defined. Data points represent values measured for extracted/purified pigments (Fig. 2), polygons represent boundaries of categories. See online Supplementary Material for a 3D version of this figure

Table 2 Rules for classification of R'G'B' images. Thr = threshold

\begin{tabular}{lccll}
\hline $\mathrm{R}^{\prime} / \mathrm{G}^{\prime}$ & $\mathrm{R}^{\prime} / \mathrm{B}^{\prime}$ & $\mathrm{G}^{\prime} / \mathrm{B}^{\prime}$ & Intensity & Category \\
\hline$>3$ & $>3$ & ignore & $\mathrm{R}^{\prime}>\mathrm{thr}$ & Chl \\
$<10$ & $<3$ & $<4$ & $\mathrm{R}^{\prime}$ and $\mathrm{B}^{\prime}>\mathrm{thr}$ & $R F P / P E$ \\
$<0.2$ & ignore & $>4$ & $\mathrm{G}^{\prime}>\mathrm{thr}$ & $C F P / G F P$ \\
\hline
\end{tabular}

images (Fig. 4c, Table 1). Coral spectra displayed the excitation/emission signature of the dominant FP and also showed the emission contribution of chlorophyll to a variable degree. Red Montipora foliosa and Oxypora sp., which contain an RFP and a pcRFP (Smith et al. 2017), respectively, had strong signals in both $450 \mathrm{~nm}$ and $530 \mathrm{~nm}$ images (Fig. 5a, Table 1), while A. millepora, brown M. foliosa, Porites lichen and Seriatopora hystrix appeared only brightly green under $450 \mathrm{~nm}$ light (Fig. 5b, Table 1). The algorithm classified green algae as $C h l$, cyan and green corals as $C F P / G F P$, and CCA and red corals as $R F P / P E$ (Figs. 4, 5, S5). A few small areas near coral polyps or margins were also classified as $C h l$, and some pixels on a brown $M$. foliosa colony were classified as $R F P / P E$ or Other (Fig. 5). Non-coralline red algae and some regions of rocks covered in algal films were classified as Other, with the exception of a few heteropigmented regions on red algae fronds which were classified as RFP/ $P E$ (Fig. 4).

\section{CMOS camera imaging}

Finally, we assessed whether CMOS cameras commonly deployed in benthic surveys could be used effectively in place of the microscope CCD camera to generate R'G'B'
MEF images. Therefore, we adapted the same illumination system to image aliquots of extracted/purified pigments with a digital compact camera (Fig. 6), using emission filters of similar optical properties to the ones mounted on the microscope filter wheel (Fig. 1a, Fig. S2). With the CMOS camera set-up, PE and amilFP597 had only background-level signal in the $G^{\prime}$ channel, making these pigments indistinguishable from extracted chlorophyll from the $450 \mathrm{~nm}$ image alone; the difference could, however, be easily resolved in the $530 \mathrm{~nm}$ image (Fig. 6). The strongest signal for amilFP497 was in the G' channel, consistent with the CCD camera results, but eechRFP had stronger signal in R' (Figs. 2, 6). All pigments produced a sufficient fluorescence signal to appear clearly above background.

We then used the same compact camera configuration at a wider angle to image an assemblage of organisms from our coral reef mesocosm (Fig. 7a). In this image, red and green corals produced a strong fluorescence signal in the R', G', and B' channels; lower intensity signal was also detected in the R' and B' channel for red algae and CCA (Fig. 7a). However, the same green macroalgae that produced clear signal in the $\mathrm{R}$ ' channel when imaged with the CCD camera did not produce above-background fluorescence in any channel when imaged with a compact camera (Figs. 4, 7a).

We also applied the MEF approach to wide-field imaging of marine organisms using the FluorIS, a modified off-the-shelf professional camera described by Treibitz et al. (2015). In this configuration the internal IR filter, which blocks most wavelengths $>650 \mathrm{~nm}$, is removed in order to improve detection of the chlorophyll-a $680 \mathrm{~nm}$ emission band. Due to a technical issue, we replaced the $530 \mathrm{~nm}$ LED with a $505 \mathrm{~nm}$ one, keeping all remaining components of the set-up the same (Fig. S2). With this 


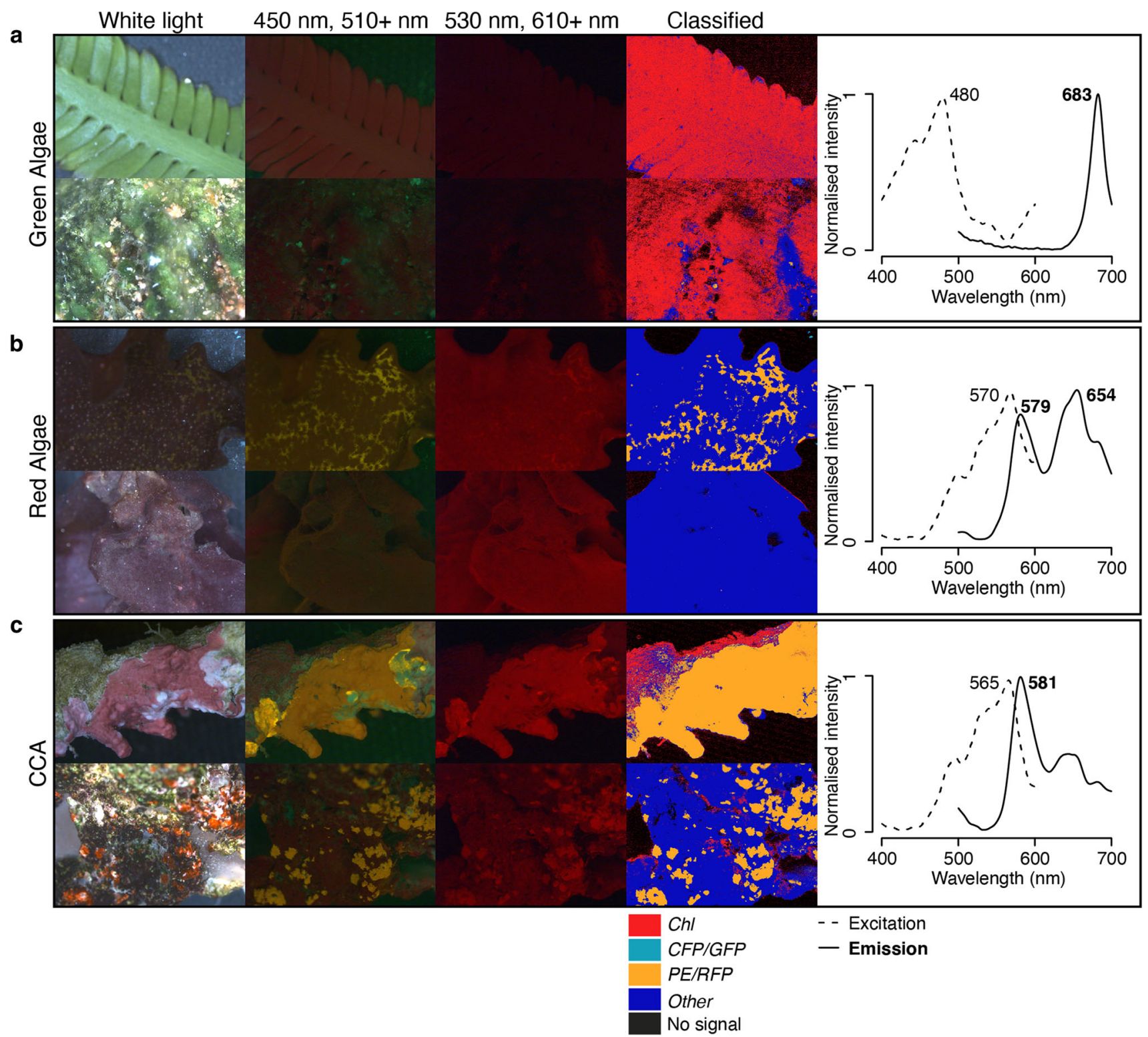

Fig. 4 Classification of multi-excitation fluorescence images of algae groups. Algae imaged with the CCD microscope camera under white light, $450 \mathrm{~nm}$ excitation $(510 \mathrm{~nm}$ emission filter $)$ and $530 \mathrm{~nm}$ excitation $(610 \mathrm{~nm}$ emission filter), results of image classification, excitation (Ex) and emission (Em) spectra with peak wavelengths $(\mathrm{nm})$. a Green algae: Caulerpa sp. (top and spectra), unidentified turf

method, Discosoma striata containing cyan and green FPs produced strong signal in the G' channel (Fig. 7b), while CCA and red macroalgae had the strongest signal in the B' channel (Fig. 7b, c). Importantly, green macroalgae and turf algae produced above background signal in both $\mathrm{R}^{\text {' }}$ and B', resulting in a clear visual contrast from CCA and red macroalgae in the R'G'B' image (Fig. 7b, c). species growing on a coral skeleton (bottom). b Red algae: unidentified fleshy macroalgae (top and spectra), unidentified turf species (bottom). c CCA: unidentified species growing on a coral skeleton (top and spectra), unidentified species growing on live rock (bottom)

\section{Discussion}

\section{System design and image processing method}

The MEF imaging method described in this study is a novel approach to functional imaging of benthic assemblages, which can be applied to characterise the keystone groups that support coral reef ecosystems as well as other aquatic ecosystems. The method relies on three key components: high-power colour LEDs to excite fluorescence in two 

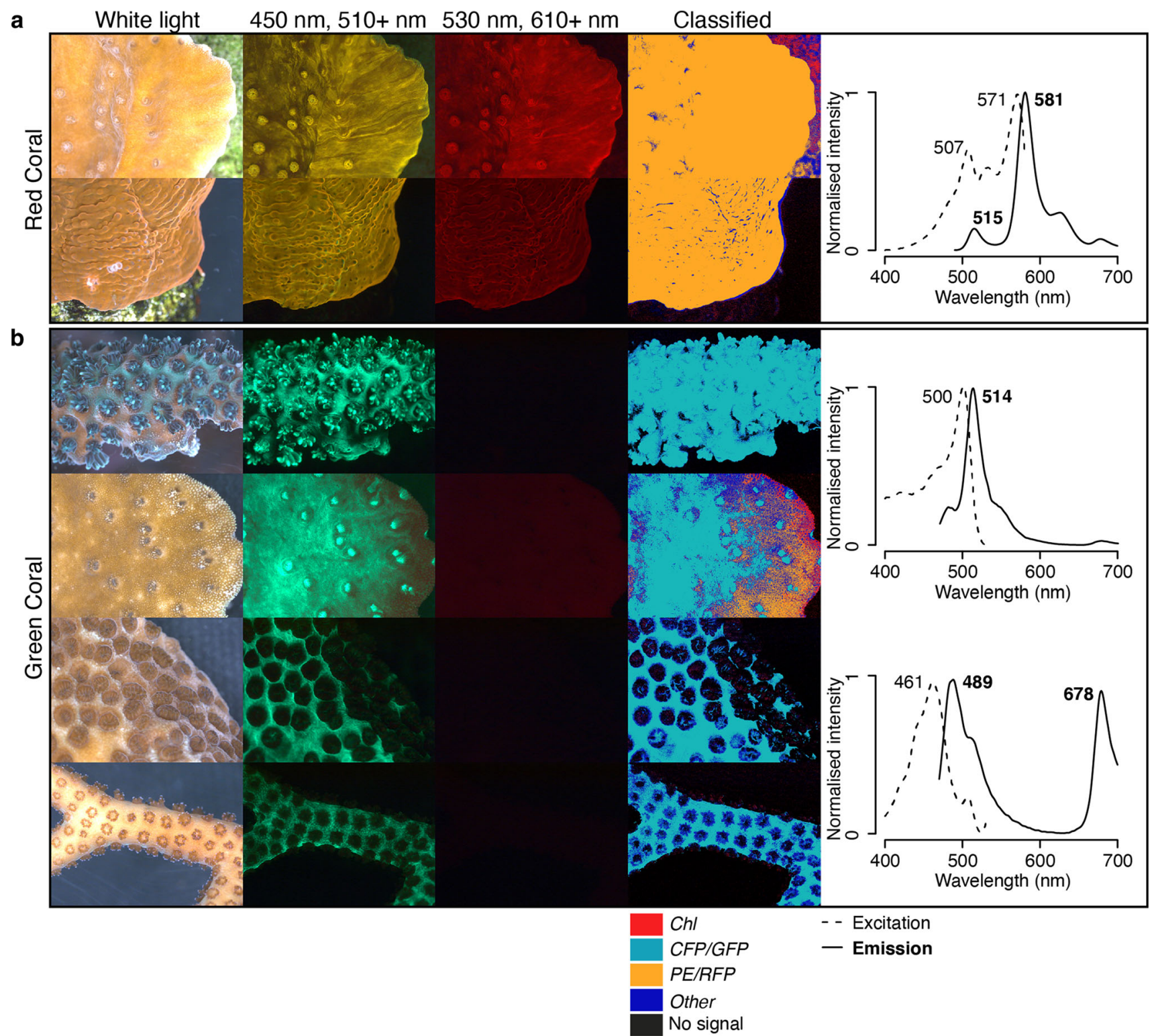

Fig. 5 Classification of multi-excitation fluorescence images of hard corals. Corals imaged with the CCD microscope camera under white light, $450 \mathrm{~nm}$ excitation $(510 \mathrm{~nm}$ emission filter $)$ and $530 \mathrm{~nm}$ excitation (610 $\mathrm{nm}$ emission filter), results of image classification, excitation (Ex) and emission (Em) spectra with peak wavelengths

spectral bands, an RGB camera detector, and simple processing of fluorescence data as pseudocolour RGB images.

The high-power LEDs used in this study provide up to 100 lumens per diode over a narrow waveband of $\sim 50$ $\mathrm{nm}$. Narrow-waveband illumination is a prerequisite of fluorescence imaging in any environment, to avoid bleedthrough of excitation light (scattered or direct) into the detector channels. In the marine environment, the excitation light source must also output enough intensity to compensate for stronger attenuation of light by water (Mazel et al. 2003) and allow a fast shutter speed to reduce (nm). a Red coral: red morph of Monitpora foliosa (top), Oxypora sp. (bottom and spectra). b Green coral: (top to bottom) Acropora millepora (top spectra), brown morph of M. foliosa, Porites lichen (bottom spectra) and Seriatopora hystrix

the effects of water movement and ambient light contamination (Mazel 2005). Commonly, illumination for underwater fluorescence photography is achieved using off-theshelf, wide spectrum professional strobes equipped with band-pass or short-pass filters (Mazel 2005; Treibitz et al. 2015); as a result, only a fraction of light emitted by the instrument is used to excite fluorescence, and multiple strobes are required to achieve sufficient output (Treibitz et al. 2015). Our LEDs are thus an ideal component for the development of a multi-excitation illumination system that can produce high intensities while keeping size, cost and 


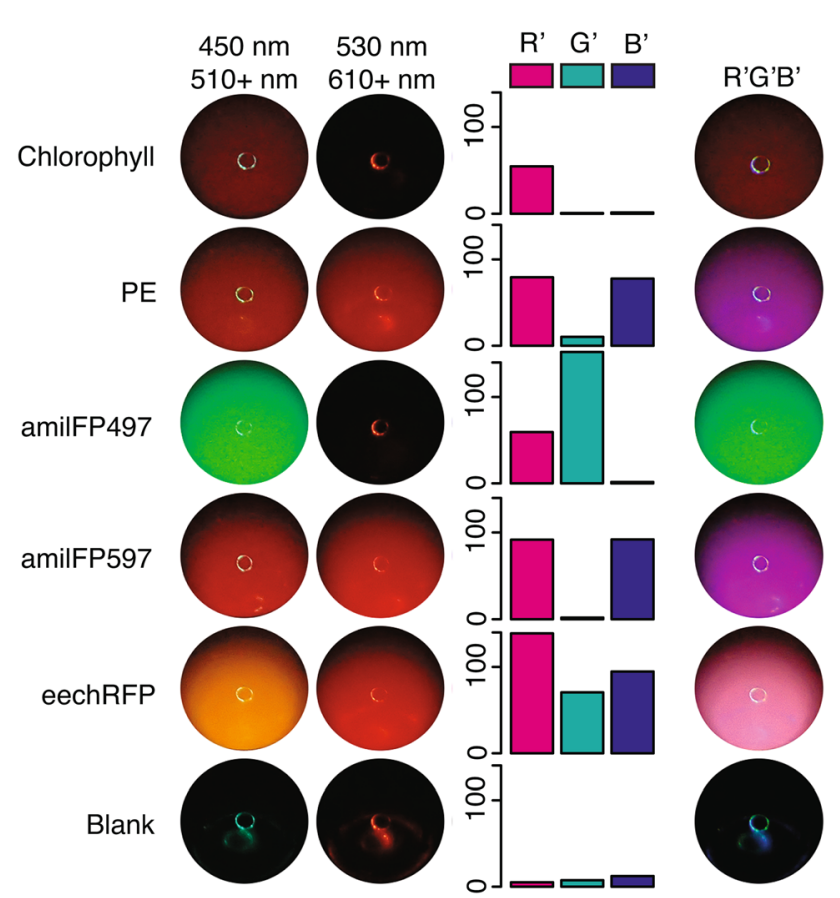

Fig. 6 Multi-excitation imaging of extracted/purified pigments with a compact CMOS camera. Pigments imaged under $450 \mathrm{~nm}$ excitation $(510 \mathrm{~nm}$ emission filter) and $530 \mathrm{~nm}$ excitation $(610 \mathrm{~nm}$ emission filter), barplots of pixel intensity in the R', G', and B' channels, and the resulting combined $\mathrm{R}^{\prime} \mathrm{G}^{\prime} \mathrm{B}$ ' image

battery requirements within practical limits. The narrow spectral width of LED light sources is also ideally suited to promote channel separation and minimise excitation light bleed-through. To further remove bleed-through contributions from the fluorescence images, we included a channelspecific background subtraction step in the image processing workflow. While this method produced good results, we note that imaging substrates with a wider range of optical properties such as highly reflective coral or sand (Hochberg et al. 2003; Enríquez et al. 2005) may accentuate the issue. Combining narrow-waveband LEDs with a short-pass excitation filter could thus further optimise the approach for field applications.

The pseudocolour RGB format provides a means to summarise all spectral information into a single frame, and results in good visual separation of the pigments in the colour space. The aim is not only to facilitate image interpretation by the user, but also to enable the application of colour or texture-based automatic classification methods developed for reflectance RGB images (Mehta et al. 2007; Stokes and Deane 2009; Beijbom et al. 2012; Mahmood et al. 2016). Our prototype imaging system was designed to eliminate or greatly reduce the need for image registration; however, we acknowledge that the need to obtain registered image pairs may pose a challenge to the application of this technique in the field (Beijbom et al. 2016). We propose the use of a custom-built framer and a post- processing registration step, an approach successfully adopted for reflectance/fluorescence image pairs obtained with two separate cameras in previous studies (Beijbom et al. 2016; Zweifler et al. 2017). Additionally, Beijbom et al. (2016) showed that the accuracy of convolutional neural network annotation improved when applied in a two-stage approach on image pairs, rather than directly on the combined image; this approach should be taken into consideration for computer vision-based analysis of MEF images.

\section{Fluorescent pigment detection by MEF imaging}

In R'G'B' images acquired with a CCD microscope camera, chlorophylls purified from green algae appear almost exclusively red, coral GFP appears green, while coral RFPs and red algae PE appear as shades of pink and purple. The $450 \mathrm{~nm}$ light source has a strong overlap with the Soret absorption band of chlorophyll-a and $b$, therefore efficiently exciting deep-red fluorescence emission (Mackinney 1941; Falkowski and Kiefer 1985); the green gap in the chlorophyll absorption spectrum, on the other hand, results in negligible excitation by the $530 \mathrm{~nm}$ light. These spectral properties cause extracted chlorophyll to be clearly defined in the R'G'B' colour space by the strong $R^{\prime}$ signal and negligible signal in the other channels. Coral GFPs and CFPs are also strongly excited by $450 \mathrm{~nm}$ light (Alieva et al. 2008); while the blue part of their spectrum is blocked by the emission filter, the rest falls almost entirely within the sensitivity of the $G$ channel of the camera sensor, resulting in clear separation of this pigment group as strong G' signal (Treibitz et al. 2015; Beijbom et al. 2016). PE and coral RFPs have similar spectral properties; both are strongly excited by $530 \mathrm{~nm}$ light, which produces the signal in the B' channel that clearly separates them from the other pigments. Orange-red fluorescence of RFPs and PE is also excited to a lesser extent by $450 \mathrm{~nm}$ light; however, emission is blue-shifted from chlorophyll fluorescence by about $100 \mathrm{~nm}$, and as such it is expected to generate additional signal in either just R', or both R' and G' channels in variable proportions depending on the spectral sensitivity of the camera sensor and on the exact emission peak of the pigment considered.

pcRFPs are a particular group of coral RFPs which emit green fluorescence upon synthesis, but are converted into a red-emitting form upon irradiation with light in the nearUV range (Ando et al. 2002; Wiedenmann et al. 2004). These proteins can produce signal in all three channels via direct excitation and emission of the unconverted green chromophore (G'), via direct excitation and emission of the converted red chromophore ( $\left.\mathrm{B}^{\prime}\right)$, and via emission of the converted red chromophore upon excitation of the unconverted green chromophore (R'), which occurs through 
a
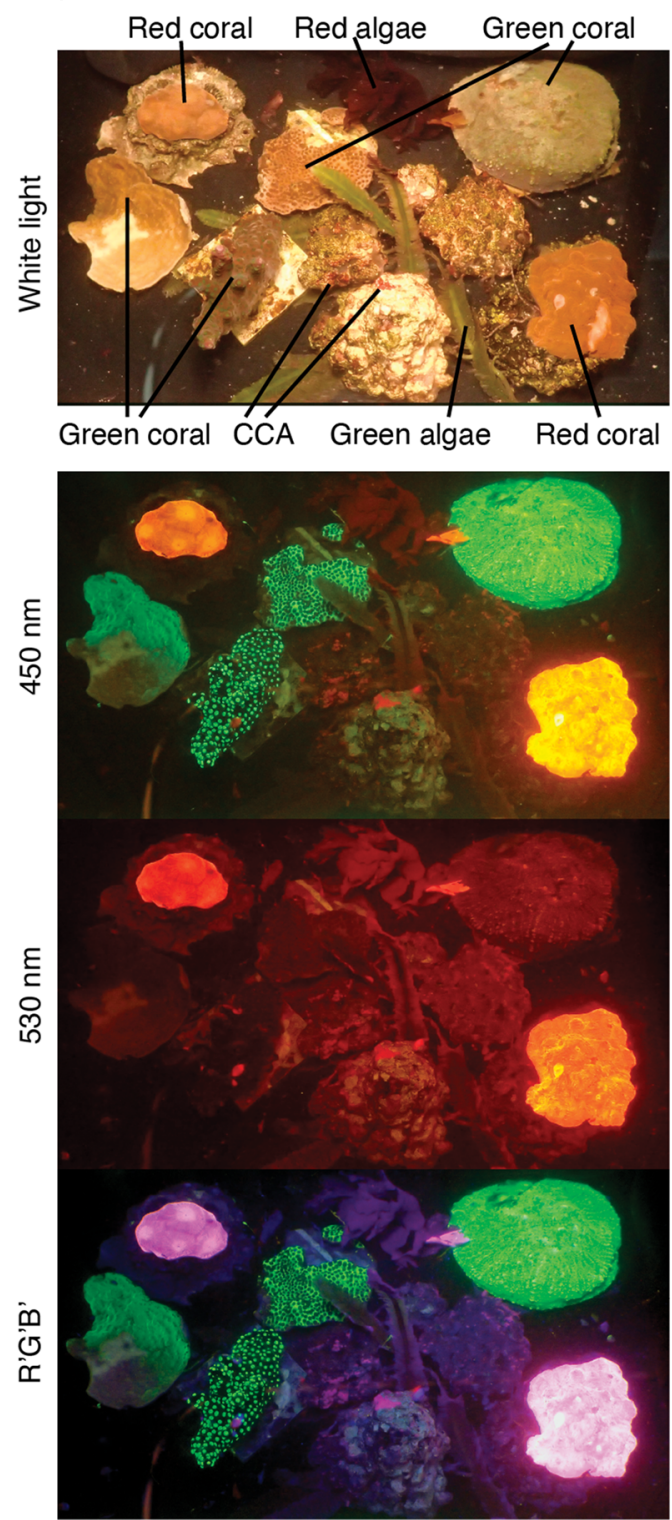

b
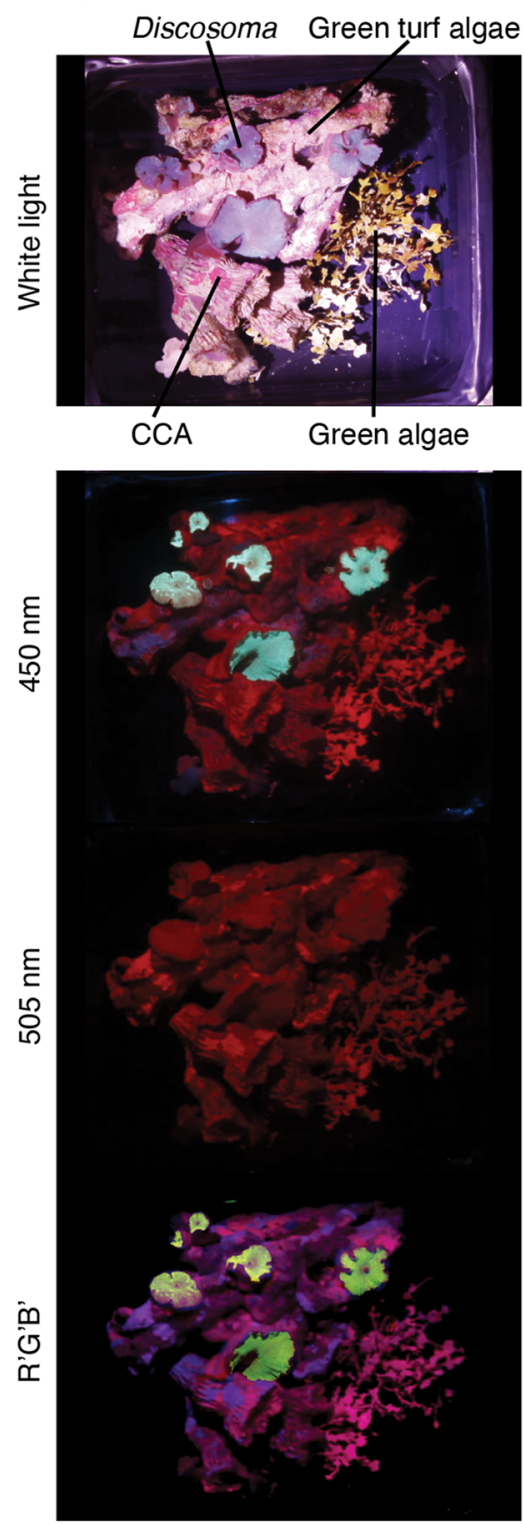

C
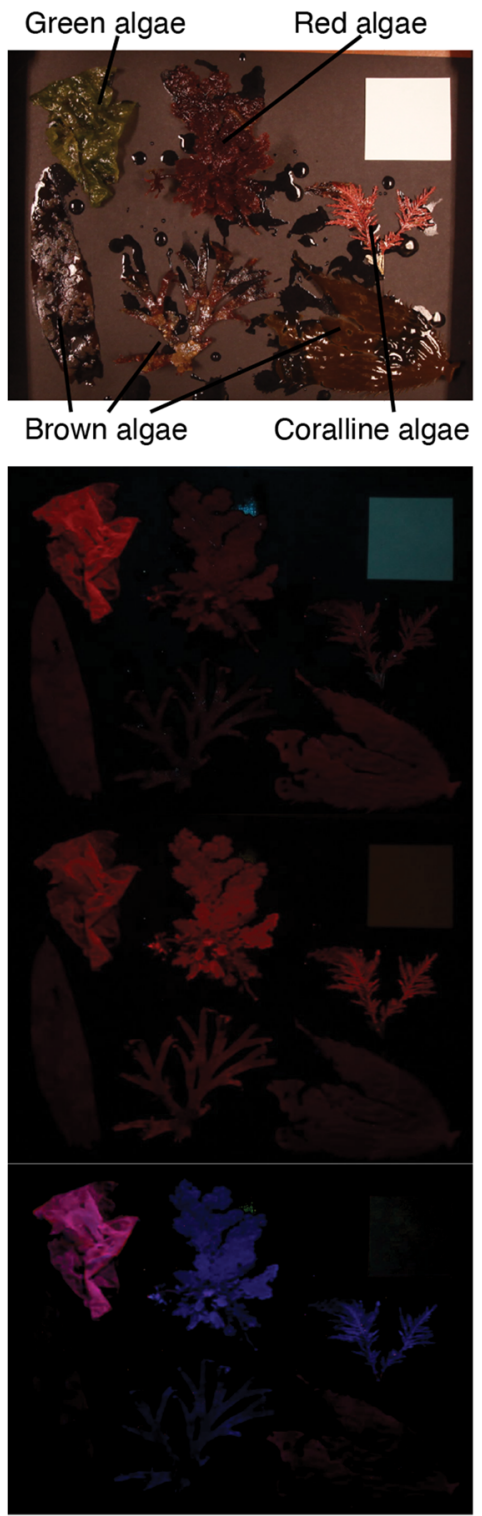

Fig. 7 Multi-excitation imaging of marine benthic organisms with CMOS cameras. a Tropical organisms imaged with a compact camera (Olympus TG-4). Tropical organisms $\mathbf{b}$ and temperate macroalgae

highly efficient Förster Resonance Energy Transfer (FRET) between adjacent protein subunits (Wiedenmann et al. 2004; Bollati et al. 2017). The relative proportions of R'G'B' signal will thus depend on the degree of photoconversion of the pcRFP pool in question. The purified pcRFP used in this study had a high proportion of unconverted, green-emitting chromophores, which conferred it a different spectral signature from other RFPs and produced $G$ ' signal when imaged with either camera. However, in shallow water environments coral pcRFPs have a higher proportion of red chromophores and emit mostly orangered fluorescence (Bollati et al. 2017); these pigments will c imaged with the FluorIS. Scenes imaged under white light, $450 \mathrm{~nm}$ excitation (510 nm emission filter), 530/505 nm excitation

thus group more closely to other orange-red pigments under MEF imaging in the field.

\section{MEF imaging and functional classification of live organisms}

Due to the high efficiency of coupling between photosynthetic pigments, fluorescence emission of intact algae occurs predominantly from de-excitation of PSII chlorophyll-a (Falkowski and Kiefer 1985); however, in green algae much of the PSII excitation energy is transferred from chlorophyll-a and $b$ molecules found in light 
harvesting complexes (Thornber 1975), while in red algae and cyanobacteria it is transferred from phycobiliproteins found in the phycobilisomes (French and Young 1952; Myers and Kratz 1955). Thus, spectral fluorescence excitation rather than emission is particularly suited to provide information about the accessory pigment composition of photosynthetic organisms, and consequently on their taxonomic and functional grouping. This is confirmed by the results of our classification algorithm and further supported by spectroscopic studies performed on micro- and macroalgae, which have shown that functional groups can be discriminated by comparing chlorophyll emission under blue and green excitation (Yentsch and Phinney 1985; Topinka et al. 1990).

Despite the very strong coupling between accessory pigments and PSII chlorophyll-a, in the case of PE some direct emission is still detectable in vivo albeit with a much lower quantum yield than what is observed for the pigment in isolation (French and Young 1952). In this study, the relative intensities of chlorophyll and $\mathrm{PE}$ emission differed between CCA and non-calcifying red macroalgae, resulting in red macroalgae being classified as a separate group by the algorithm. The concentrations of the two pigments are known to vary interspecifically within the red algae (Kim et al. 2007); these differences could thus be exploited to improve classification in this category by developing an algorithm that accounts for pigment combinations. This kind of algorithm could also allow further discrimination between CCA and red corals, which do not currently separate in the R'G'B' space under the CCD camera due to spectral overlap between PE, RFPs and pcRFPs (Oswald et al. 2007). The rationale for this is that as well as red fluorescence, RFP-containing corals usually also emit fluorescence in the cyan or green spectral range, either through co-expression of multiple FPs (D'Angelo et al. 2008), or due to incomplete maturation of the red chromophore which is typical of both dsRed-type and pcRFPtype coral pigments (Matz et al. 1999; Baird et al. 2000; Ando et al. 2002; Wiedenmann et al. 2004); the combined signal could therefore be used to confidently separate corals from other groups. It should also be noted that confusion of CCA with hard coral is not commonly an issue for manual or automatic classification in reflectance images (Beijbom et al. 2012, 2015), and we therefore expect that machine learning algorithms will have no issue discriminating between these groups in R'G'B' images. Integrating R'G'B' colour with other image properties currently used by computer vision models, such as texture (Mehta et al. 2007; Stokes and Deane 2009; Beijbom et al. 2012), or combining fluorescence images with reflectance ones (Beijbom et al. 2016) might further facilitate this classification.

\section{MEF imaging with off-the-shelf cameras}

Waterproof point-and-shoot compact cameras, which mount $1 / 2.3^{\prime \prime}$ CMOS sensors, are one of the most accessible and portable imaging tools used in benthic surveys. When combined with our dual-LED excitation system, this type of compact camera was effective in imaging all purified pigments, which separated clearly in the R'G'B' space. Importantly, under the CMOS camera the information provided by the $530 \mathrm{~nm}$ image and conveyed by the B' channel was the sole discriminant between chlorophyll and $\mathrm{PE} / \mathrm{RFPs}$, while under the CCD camera this separation was possible based on $\mathrm{R}^{\prime}$ and G' signal alone. This is due to different channel sensitivity of the two sensors, which causes PE and RFP to produce some G' signal in the CCD camera but not in the CMOS camera. This clearly illustrates that adopting a MEF approach for in situ imaging can improve fluorescence-based classification, offering a definite advantage over methods based on a single excitation band particularly when using a CMOS camera to capture the fluorescence signal.

While extracted chlorophyll was easily detected by the CMOS compact camera in the R' channel, red fluorescence of chlorophyll-containing organisms was low when imaged in vivo. This is due to photochemical quenching of PSII excitation, which occurs via reduction of plastoquinone in the thylakoid membranes of chloroplasts resulting in lower fluorescence yield (Falkowski and Kiefer 1985). Additionally, off-the-shelf camera sensors are usually fitted with an IR-blocking filter to mimic the sensitivity of the human eye and obtain more realistic images; the IR filter cut-on partially overlaps the PSII emission band, causing the R' signal reduction observed with the compact CMOS camera compared to the microscope CCD camera (Treibitz et al. 2015). To improve detection of chlorophyll fluorescence in underwater images, Treibitz et al. (2015) developed the FluorIS, an off-the-shelf professional camera modified to remove the IR filter; this configuration has been extensively used in daytime wide-angle imaging of coral reef benthos, to improve automatic image annotation, and in surveys of coral recruits (Treibitz et al. 2015; Beijbom et al. 2016; Zweifler et al. 2017). Our images show that combining this approach with MEF LEDs and filters provides enhanced detection of chlorophyll emission in both R' and B' channels, allowing good separation of functional groups of photosynthetic organisms based on the excitation spectrum of their dominant accessory pigments. Thus, we suggest that the FluorIS is an ideal detector for use with our MEF system for field imaging of benthic assemblages on coral reefs and other aquatic ecosystems. 


\section{Beyond classification: benthic fluorescence as a physiological biomarker}

Our study has shown that MEF imaging is a promising new approach to coral reef surveys, which we hope will underpin the design of a benthic imaging system based on accessible components to improve automatic classification and facilitate analysis of large datasets (Beijbom et al. 2016). The excitation and emission wavebands could be further customised to target only specific pigments or organisms by changing the LED and filter combinations, making this a flexible instrument for different survey purposes.

While this study has focused on the applications of MEF for classification into benthic groups, the approach can also be used to develop novel monitoring methods based on in situ imaging. As well as being a discriminant between groups, in fact, fluorescent pigments have potential to act as biomarkers of physiological processes within groups of organisms. For example, the relative proportions of chlorophyll and PE are known to vary intraspecifically with photoacclimation in CCA (Payri et al. 2001), a shift that may be detected from changes in the R'/B' ratio in R' $\mathrm{G}^{\prime} \mathrm{B}$ ' images. In corals, the relative proportions of fluorescence signal in different spectral bands are also known to change with environmental conditions, either via differential regulation of multiple FPs, or via light-driven photoconversion. Changes in coral FP fluorescence have thus been used in laboratory settings as biomarkers of photoacclimation, defense against epibionts, growth and repair processes, heat stress, nutrient stress and bleaching (Zawada and Jaffe 2003; D'Angelo et al. 2008, 2012; Smith-Keune and Dove 2008; Bollati et al. 2020). Specifically, bleaching caused by exposure to brief episodes of heat stress or prolonged mild heat or nutrient stress can result in a reef-wide dramatic increase in coral fluorescence (Bollati et al. 2020). Clearly, our method can facilitate the automated analysis of these biomarkers in situ.

The optical properties of reef organisms may also be used to monitor interactions between corals and other taxa that have detrimental effects on reef health. For example, strains of cyanobacteria with different spectral signatures are associated with widespread coral syndromes, such as red band and black band disease (Sussman et al. 2006). Our approach could therefore be used to image the interface between healthy and diseased tissue, providing a non-invasive tool for monitoring disease progression. Similarly, spectral imaging may be used to target the interface between coral and turf algae (Barott et al. 2009); these interfaces affect coral health due to interactions between corals and the algal microbiome (Smith et al. 2006) and are important to assess how reefs recover following disturbance (Diaz-Pulido et al. 2009). Finally, while we have primarily discussed the potential applications of MEF imaging for coral reef assemblages, the method can be applied to survey a wide range of shallow water benthic ecosystems. For example, MEF imaging of PE fluorescence could be used to non-invasively identify live thalli on maerl beds, which are a highly biodiverse temperate ecosystem with priority conservation status in European legislation (Barbera et al. 2003).

Future work should focus on optimising the method for field image acquisition and explore the application of computer vision for MEF image analysis. In summary, our method has a great potential to produce high information content benthic surveys in coral reefs and other suitable marine habitats.

Supplementary Information The online version contains supplementary material available at https://doi.org/10.1007/s00338021-02101-1.

Acknowledgements The authors thank Robbie Robinson and George Clark for skilful maintenance of the coral mesocosm at the University of Southampton. We are grateful to Misha Matz, University of Texas at Austin, for sharing the EechRFP vector. We also thank the Birch Aquarium at Scripps for providing organisms for imaging, and Cathryn Quick, University of Southampton, for collecting macroalgae samples. The authors acknowledge funding from Natural Environmental Research Council (http://www.nerc.ac.uk/; PhD studentship under NE/L002531/1 to E.B.; NE/I01683X/1, NE/K00641X/1, and NE/I012648/1 to J.W. and C.D.), Deutsche Forschungsgemeinschaft (http://www.dfg.de; Wi1990/2-1 to J.W.), ASSEMBLE (to J.W. and C.D.), the European Research Council (http://erc.europa.eu/) under the European Union's Seventh Framework Programme (ERC grant agreement no. 311179 to J.W.), Tropical Marine Centre London, and Tropic Marin, Wartenberg (NERC CASE studentship to E.B.; sponsorship to the Coral Reef Laboratory).

Authors' contributions E.B., C.D.A. and J.W. contributed to conceptualisation. E.B., C.D.A. and J.W. contributed to methodology. E.B. performed formal analysis. E.B. conducted investigation. J.W., D.K. and B.G.M. contributed resources. E.B. was involved in writing-original draft preparation. E.B., C.D.A., D.K., J.W. were involved in writing-review and editing. E.B. contributed to visualisation. J.W., D.K., C.D.A., B.G.M were involved in supervision.

Data availability Code for image processing and classification algorithm is available from GitHub.com/ElenaBollati/MEF. All data are available from the corresponding author upon reasonable request.

\section{Declarations}

Conflict of interest On behalf of all authors, the corresponding author states that there is no conflict of interest.

Open Access This article is licensed under a Creative Commons Attribution 4.0 International License, which permits use, sharing, adaptation, distribution and reproduction in any medium or format, as long as you give appropriate credit to the original author(s) and the source, provide a link to the Creative Commons licence, and indicate if changes were made. The images or other third party material in this article are included in the article's Creative Commons licence, unless indicated otherwise in a credit line to the material. If material is not included in the article's Creative Commons licence and your intended 
use is not permitted by statutory regulation or exceeds the permitted use, you will need to obtain permission directly from the copyright holder. To view a copy of this licence, visit http://creativecommons. org/licenses/by/4.0/.

\section{References}

Alieva NO, Konzen KA, Field SF, Meleshkevitch EA, Hunt ME, Beltran-Ramirez V, Miller DJ, Wiedenmann J, Salih A, Matz MV (2008) Diversity and evolution of coral fluorescent proteins. PLoS ONE 3:e2680

Ando R, Hama H, Yamamoto-Hino M, Mizuno H, Miyawaki A (2002) An optical marker based on the UV-induced green-to-red photoconversion of a fluorescent protein. Proc Natl Acad Sci 99:12651-12656

Andréfouët S, Payri C, Hochberg E, Hu C, Atkinson M, MullerKarger F (2004) Use of in situ and airborne reflectance for scaling-up spectral discrimination of coral reef macroalgae from species to communities. Mar Ecol Prog Ser 283:161-177

Anthony KRN, Kline DI, Diaz-Pulido G, Dove S, Hoegh-Guldberg O (2008) Ocean acidification causes bleaching and productivity loss in coral reef builders. Proc Natl Acad Sci 105:17442-17446

Baird GS, Zacharias DA, Tsien RY (2000) Biochemistry, mutagenesis, and oligomerization of DsRed, a red fluorescent protein from coral. Proc Natl Acad Sci 97:11984-11989

Bak RPM (1976) The growth of coral colonies and the importance of crustose coralline algae and burrowing sponges in relation with carbonate accumulation. Netherlands J Sea Res 10:285-337

Barbera C, Bordehore C, Borg JA, Glémarec M, Grall J, Hall-Spencer JM, De La Huz CD, Lanfranco E, Lastra M, Moore PG, Mora J, Pita ME, Ramos-Esplá AA, Rizzo M, Sánchez-Mata A, Seva A, Schembri PJ, Valle C (2003) Conservation and management of northeast Atlantic and Mediterranean maerl beds. Aquat Conserv Mar Freshw Ecosyst 13:65-76

Barott K, Smith J, Dinsdale E, Hatay M, Sandin S, Rohwer F (2009) Hyperspectral and physiological analyses of coral-algal interactions. PLoS ONE 4(11):e8043

Beijbom O, Edmunds PJ, Kline DI, Mitchell BG, Kriegman D (2012) Automated annotation of coral reef survey images. IEEE Conference on Computer Vision and Pattern Recognition 2012:1170-1177

Beijbom O, Edmunds PJ, Roelfsema C, Smith J, Kline DI, Neal BP, Dunlap MJ, Moriarty V, Fan TY, Tan CJ, Chan S, Treibitz T, Gamst A, Mitchell BG, Kriegman D (2015) Towards automated annotation of benthic survey images: variability of human experts and operational modes of automation. PLoS ONE 10:e130312

Beijbom O, Treibitz T, Kline DI, Eyal G, Khen A, Neal B, Loya Y, Mitchell BG, Kriegman D (2016) Improving automated annotation of benthic survey images using wide-band fluorescence. Sci Rep 6:23166

Bollati E, Plimmer D, D'Angelo C, Wiedenmann J (2017) FRETmediated long-range wavelength transformation by photoconvertible fluorescent proteins as an efficient mechanism to generate orange-red light in symbiotic deep water corals. Int $\mathbf{J}$ Mol Sci 18:1174

Bollati E, D'Angelo C, Alderdice R, Pratchett M, Ziegler M, Wiedenmann J (2020) Optical feedback loop involving dinoflagellate symbiont and scleractinian host drives colorful coral bleaching. Curr Biol 30:1-13

Chennu A, Färber P, De'ath G, de Beer D, Fabricius KE, (2017) A diver-operated hyperspectral imaging and topographic surveying system for automated mapping of benthic habitats. Sci Rep $7: 7122$
D'Angelo C, Wiedenmann J (2012) An experimental mesocosm for long-term studies of reef corals. J Mar Biol Assoc United Kingdom 92:769-775

D'Angelo C, Wiedenmann J (2014) Impacts of nutrient enrichment on coral reefs: new perspectives and implications for coastal management and reef survival. Curr Opin Environ Sustain 7:82-93

D'Angelo C, Denzel A, Vogt A, Matz M, Oswald F, Salih A, Nienhaus G, Wiedenmann J (2008) Blue light regulation of host pigment in reef-building corals. Mar Ecol Prog Ser 364:97-106

D'Angelo C, Smith EG, Oswald F, Burt J, Tchernov D, Wiedenmann J (2012) Locally accelerated growth is part of the innate immune response and repair mechanisms in reef-building corals as detected by green fluorescent protein (GFP)-like pigments. Coral Reefs 31:1045-1056

Diaz-Pulido G, McCook LJ, Dove S, Berkelmans R, Roff G, Kline DI, Weeks S, Evans RD, Williamson DH, Hoegh-Guldberg O (2009) Doom and boom on a resilient reef: climate change, algal overgrowth and coral recovery. PLoS ONE 4(4):e5239

Dove SG, Hoegh-Guldberg O, Ranganathan S (2001) Major colour patterns of reef-building corals are due to a family of GFP-like proteins. Coral Reefs 19:197-204

Enríquez S, Méndez ER, Iglesias-Prieto R (2005) Multiple scattering on coral skeletons enhances light absorption by symbiotic algae. Limnol Oceanogr 50:1025-1032

Fabricius KE (2005) Effects of terrestrial runoff on the ecology of corals and coral reefs: review and synthesis. Mar Pollut Bull 50:125-146

FabriciusDe'ath KEG (2001) Environmental factors associated with the spatial distribution of crustose coralline algae on the Great Barrier Reef. Coral Reefs 19:303-309

Falkowski P, Kiefer DA (1985) Chlorophyll a fluorescence in phytoplankton: relationship to photosynthesis and biomass. J Plankton Res 7:715-731

French CS, Young VK (1952) The fluorescence spectra of red algae and the transfer of energy from phycoerythrin to phycocyanin and chlorophyll. J Gen Physiol 35:873-890

Garcia RA, Lee Z, Hochberg EJ (2018) Hyperspectral shallow-water remote sensing with an enhanced benthic classifier. Remote Sens 10:147

Gittins JR, D'Angelo C, Oswald F, Edwards RJ, Wiedenmann J (2015) Fluorescent protein-mediated colour polymorphism in reef corals: multicopy genes extend the adaptation/acclimatization potential to variable light environments. Mol Ecol 24:453-465

Gleason ACR, Reid RP, Voss KJ (2007) Automated classification of underwater multispectral imagery for coral reef monitoring. Oceans Conference Record (IEEE), pp 1-8. https://doi.org/10. 1109/OCEANS.2007.4449394

González-Rivero M, Bongaerts P, Beijbom O, Pizarro O, Friedman A, Rodriguez-Ramirez A, Upcroft B, Laffoley D, Kline D, Bailhache C, Vevers R, Hoegh-Guldberg O (2014) The Catlin Seaview Survey-kilometre-scale seascape assessment, and monitoring of coral reef ecosystems. Aquat Conserv Mar Freshw Ecosyst 24:184-198

Goreau TF (1963) Calcium carbonate deposition by coralline algae and corals in relation to their roles as reef-builders. Ann N Y Acad Sci 109:127-167

Heyward AJ, Negri AP (1999) Natural inducers for coral larval metamorphosis. Coral Reefs 18:273-279

Hochberg EJ, Atkinson MJ, Andréfouët S (2003) Spectral reflectance of coral reef bottom-types worldwide and implications for coral reef remote sensing. Remote Sens Environ 85:159-173

Hughes TP, Rodrigues MJ, Bellwood DR, Ceccarelli D, HoeghGuldberg O, McCook L, Moltschaniwskyj N, Pratchett MS, 
Steneck RS, Willis B (2007) Phase shifts, herbivory, and the resilience of coral reefs to climate change. Curr Biol 17:360-365

Hughes TP, Anderson KD, Connolly SR, Heron SF, Kerry JT, Lough JM, Baird AH, Baum JK, Berumen ML, Bridge TC, Claar DC, Eakin CM, Gilmour JP, Graham NAJ, Harrison H, Hobbs J-PA, Hoey AS, Hoogenboom M, Lowe RJ, McCulloch MT, Pandolfi JM, Pratchett M, Schoepf V, Torda G, Wilson SK (2018) Spatial and temporal patterns of mass bleaching of corals in the Anthropocene. Science 359:80-83

Jeffrey SW, Mantoura RFC, Wright SW (1997) Phytoplankton pigments in oceanography: guidelines to modern methods. UNESCO, Paris

Jokiel PL, Rodgers K, Kuffner I, Andersson A, Cox E, Mackenzie F (2008) Ocean acidification and calcifying reef organisms: a mesocosm investigation. Coral Reefs 27:473-483

Jokiel PL, Rodgers KS, Brown EK, Kenyon JC, Aeby G, Smith WR, Farrell F (2015) Comparison of methods used to estimate coral cover in the Hawaiian Islands. PeerJ 3:e954

Kim JK, Kraemer GP, Neefus CD, Chung IK, Yarish C (2007) Effects of temperature and ammonium on growth, pigment production and nitrogen uptake by four species of Porphyra (Bangiales, Rhodophyta) native to the New England coast. J Appl Phycol 19:431-440

Knowlton N (2010) Coral reef biodiversity. In: McIntyre AD (ed) Life in the World's Oceans: Diversity, Distribution, and Abundance. Wiley-Blackwell, Chichester, UK, pp 65-77

Kuffner IB, Walters LJ, Becerro MA, Paul VJ, Ritson-Williams R, Beach KS (2006) Inhibition of coral recruitment by macroalgae and cyanobacteria. Mar Ecol Prog Ser 323:107-117

Kuffner IB, Andersson AJ, Jokiel PL, Rodgers KS, Mackenzie FT (2008) Decreased abundance of crustose coralline algae due to ocean acidification. Nat Geosci 1:114-117

Kutser T, Miller I, Jupp DLB (2006) Mapping coral reef benthic substrates using hyperspectral space-borne images and spectral libraries. Estuar Coast Shelf Sci 70:449-460

Loya Y (2004) The coral reefs of Eilat-Past, present and future: three decades of coral community structure studies. Coral Health and Disease. Springer, Berlin Heidelberg, Berlin, Heidelberg, pp $1-34$

Mackinney G (1941) Absorption of light by chlorophyll. J Biol Chem 140:315-322

Mahmood A, Bennamoun M, An S, Sohel F, Boussaid F, Hovey R, Kendrick G, Fisher RB (2016) Coral classification with hybrid feature representations. IEEE International Conference on Image Processing (ICIP) 2016:519-523

Matz MV, Fradkov AF, Labas YA, Savitsky AP, Zaraisky AG, Markelov ML, Lukyanov SA (1999) Fluorescent proteins from nonbioluminescent Anthozoa species. Nat Biotechnol 17:969-973

Mazel CH (2005) Underwater fluorescence photography in the presence of ambient light. Limnol Oceanogr Methods 3:499-510

Mazel CH, Strand MP, Lesser MP, Crosby MP, Coles B, Nevis AJ (2003) High resolution determination of coral reef bottom cover from multispectral fluorescence laser line scan imagery. Limnol Oceanogr 48:522-534

Mehta A, Ribeiro E, Gilner J, Woesik R Van (2007) Coral reef texture classification using support vector machines. Proceedings of the Second International Conference on Computer Vision Theory and Applications - IU/MTSV:302-305

Morse DE, Hooker N, Morse ANC, Jensen RA (1988) Control of larval metamorphosis and recruitment in sympatric agariciid corals. J Exp Mar Bio Ecol 116:193-217

Myers J, Kratz WA (1955) Relations between pigment content and photosynthetic characteristics in a blue-green alga. J Gen Physiol 39:11-22
Ninio R, Delean S, Osborne K, Sweatman H (2003) Estimating cover of benthic organisms from underwater video images: variability associated with multiple observers. Mar Ecol Prog Ser 265:107-116

Oswald F, Schmitt F, Leutenegger A, Ivanchenko S, D'Angelo C, Salih A, Maslakova S, Bulina M, Schirmbeck R, Nienhaus GU, Matz MV, Wiedenmann J (2007) Contributions of host and symbiont pigments to the coloration of reef corals. FEBS $\mathrm{J}$ 274:1102-1122

Payri CE, Maritorena S, Bizeau C, Rodière M (2001) Photoacclimation in the tropical coralline alga Hydrolithon onkodes (Rhodophyta, Corallinaceae) from a French Polynesian reef. J Phycol 37:223-234

Pizarro O, Rigby P, Johnson-Roberson M, Williams SB, Colquhoun J (2008) Towards image-based marine habitat classification. Oceans 2008:1-7

Quick C, D'Angelo C, Wiedenmann J (2018) Trade-offs associated with photoprotective green fluorescent protein expression as potential drivers of balancing selection for color polymorphism in reef corals. Front Mar Sci 5:1-11

Salih A, Larkum A, Cox G, Kühl M, Hoegh-Guldberg O (2000) Fluorescent pigments in corals are photoprotective. Nature 408:850-853

Schindelin J, Arganda-Carreras I, Frise E, Kaynig V, Longair M, Pietzsch T, Preibisch S, Rueden C, Saalfeld S, Schmid B, Tinevez J-Y, White DJ, Hartenstein V, Eliceiri K, Tomancak P, Cardona A (2012) Fiji: an open-source platform for biologicalimage analysis. Nat Methods 9:676-682

Shihavuddin ASM, Gracias N, Garcia R, Gleason ACR, Gintert B (2013) Image-based coral reef classification and thematic mapping. Remote Sens 5:1809-1841

Smith EG, D'Angelo C, Sharon Y, Tchernov D, Wiedenmann J (2017) Acclimatization of symbiotic corals to mesophotic light environments through wavelength transformation by fluorescent protein pigments. Proc R Soc London B Biol Sci 284:20170320

Smith JE, Shaw M, Edwards RA, Obura D, Pantos O, Sala E, Sandin SA, Smriga S, Hatay M, Rohwer FL (2006) Indirect effects of algae on coral: algae-mediated, microbe-induced coral mortality. Ecol Lett 9:835-845

Smith-Keune C, Dove S (2008) Gene expression of a green fluorescent protein homolog as a host-specific biomarker of heat stress within a reef-building coral. Mar Biotechnol 10:166-180

Soriano M, Marcos S, Saloma C, Quibilan M, Alino P (2001) Image classification of coral reef components from underwater color video. MTS/IEEE Ocean 2001 An Ocean Odyssey Conf Proc (IEEE Cat No01CH37295) 2:1008-1013

Spalding M, Ravilious C, Green EP (2001) World atlas of coral reefs. Univ of California Press,

Stokes MD, Deane GB (2009) Automated processing of coral reef benthic images. Limnol Oceanogr Methods 7:157-168

Strand MP, Coles BW, Nevis AJ, Regan RF (1997) Laser line-scan fluorescence and multispectral imaging of coral reef environments. 2963:790-795. https://doi.org/10.1117/12.266401

Strickland JD, Parson TR (1972) A practical handbook of seawater analysis. Fisheries Research Board of Canada, Ottawa

Sussman M, Bourne DG, Willis BL (2006) A single cyanobacterial ribotype is associated with both red and black bands on diseased corals from Palau. Dis Aquat Organ 69:111-118

Thévenaz P, Ruttimann UE, Unser M (1998) A pyramid approach to subpixel registration based on intensity. IEEE Trans Image Process 7:27-41

Thornber JP (1975) Chlorophyll-proteins: light-harvesting and reaction center components of plants. Annu Rev Plant Physiol $26: 127-158$ 
Topinka JA, Korjeff Bellows W, Yentsch CS (1990) Characterization of marine macroalgae by fluorescence signatures. Int J Remote Sens 11:2329-2335

Tracey JI, Ladd HS, Hoffmeister JE (1948) Reefs of Bikini, Marshall Islands. Bull Geol Soc Am 59:861-878

Treibitz T, Neal BP, Kline DI, Beijbom O, Roberts PLD, Mitchell BG, Kriegman D (2015) Wide field-of-view fluorescence imaging of coral reefs. Sci Rep 5:7694

Wiedenmann J, Elke C, Spindler K-D, Funke W (2000) Cracks in the $\beta$-can: fluorescent proteins from Anemonia sulcata (Anthozoa, Actinaria). Proc Natl Acad Sci 97:14091-14096

Wiedenmann J, Schenk A, Röcker C, Girod A, Spindler K-D, Nienhaus GU (2002) A far-red fluorescent protein with fast maturation and reduced oligomerization tendency from Entacmaea quadricolor (Anthozoa, Actinaria). Proc Natl Acad Sci 99:11646-11651

Wiedenmann J, Ivanchenko S, Oswald F, Schmitt F, Röcker C, Salih A, Spindler K-D, Nienhaus GU (2004) EosFP, a fluorescent marker protein with UV-inducible green-to-red fluorescence conversion. Proc Natl Acad Sci U S A 101:15905-15910

Yentsch CS, Phinney DA (1985) Spectral fluorescence: An ataxonomic tool for studying the structure of phytoplankton populations. J Plankton Res 7:617-632

Zawada DG, Jaffe JS (2003) Changes in the fluorescence of the Caribbean coral Montastraea faveolata during heat-induced bleaching. Limnol Oceanogr 48:412-425

Zawada DG, Mazel CH (2014) Fluorescence-based classification of Caribbean coral reef organisms and substrates. PLoS ONE 9:e84570

Zweifler A, Akkaynak D, Mass T, Treibitz T (2017) In situ analysis of coral recruits using fluorescence imaging. Front Mar Sci 4:273

Publisher's Note Springer Nature remains neutral with regard to jurisdictional claims in published maps and institutional affiliations. 